\title{
AVALIAÇÃO INSTITUCIONAL
}

\section{Resumo}

O presente artigo pretende esclarecer à comunidade acadêmica o estudo e análise de legislações referentes à Avaliação Institucional de Cursos e Ensino Superior, tendo como base o Programa de Avaliação Institucional das Universidades Brasileiras (PAIUB). O texto é estruturado a partir de um contexto social, econômico e político que define a concepção educacional e a necessidade de se avaliar o sistema educacional brasileiro. À análise, seguem cinco ordens de pensamento: a primeira, explica o que é avaliação interna e externa; a segunda, comenta para quê avaliar; a terceira, esclarece o quê avaliar; a quarta, orienta como avaliar e, a quinta, considera quem se beneficia com a avaliação. $\mathrm{O}$ esclarecimento é detalhado também com comentários acerca dos indicadores de bom desempenho relatados no fórum Reflexivo da Universidade de Santa Catarina , em 1995 e 1996. Um comentário da comissão de professores sobre o conceito contraditório da avaliação e, uma tomada de posição a favor do ensinar a aprender dos alunos, constitui a parte conclusiva do artigo.

\section{Abstract}

The present article intends to clarify the academic community with an analysis of legislation concerning institutional Evaluation for Courses and High Education having as support the Brazilian Universities Institutional Evaluation Program (PAIUB). This paper is structured through a political, social and economic context which defines the educational concept and the need of evaluating the Brazilian educational system. The analysis consists of five parts: first, one explains what is the difference between intern and extern evaluation; second, are discussed the objectives of evaluation: third, what are the evaluation contents; fourth, how to carry out the evaluation and fifth, to whom the evaluation benefits. The explanation is completed with good issues from the University Saint Catherine Reflexive Forum in 1995 and 1996. In addition, is presented a commentary from a teacher's commission about the contradictory concept of evaluation and at last, it's expressed a point of view related to student'role in the teaching and learning process.

presente trabalho é resultado de uma pesquisa em legislações que tratam da avaliação das universidades brasileiras.

Escolhemos esse tema por ser envolvente no que diz respeito à família, à escola e à própria sociedade em grandes discussões sobre o desempenho dos filhos, dos alunos e das universidades nas provas do SARESP. Sistema de Avaliação do Rendimento Escolar do Estado de São Paulo . ENEM - Exame Nacional do Ensino Médio e PROVÃO- avaliação final de cursos .

O SARESP é um sistema de avaliação de desempenho dos alunos do Ensino Fundamental e Médio do Estado de São Paulo, que busca , através dos resultados da verificação dos rendimentos dos alunos, nortear os trabalhos pedagógicos das instâncias escolares e Diretorias Regionais, além de fornecer dados ao sistema de ensino. Implementado em 1996, busca criar e manter uma rede contínua de informação entre a Secretaria de Estado da Educação e as unidades escolares, procurando oferecer subsídios à gestão educacional e, principalmente, implantando uma cultura avaliativa no Estado de São Paulo. Além do conhecimento do perfil dos alunos, a Secretaria da Educação objetiva que a avaliação deixe a sua antiga forma de classificar os alunos

*Professora do Curso de Pedagogia das Faculdades Integradas "Campos Salles" 
em "incapazes" ou "deficientes", para uma avaliação diagnóstica de situação de aprendizagem, visando à otimização das possibilidades do ensino. Uma avaliação diagnóstica facilitará ao professor a adoção de estratégias apropriadas de ensino e aprendizagem e, ao mesmo tempo, contribuirá para a melhoria da gestão do sistema educacional. É essa forma de avaliar que é denominada avaliação formativa, que tem por base a crença de que o aluno aprende e quer aprender, por isso, a sua lógica é a interação, cooperação, mudança de prática de ensino na sala de aula, uma gestão inovadora da aula, um ensino diferenciado e outros meios que favorecem a aprendizagem dos alunos.

No ensino médio, vimos O ENEM, cujo perfil é avaliar o aluno prestes a se formar ou já formado, esperando que possua:

"-domínio dos princípios científicos e tecnológicos que presidem a produção moderna;

-conhecimento das formas contemporâneas de linguagem;

-domínio dos conhecimentos de filosofia e Sociologia necessários à cidadania."(art.36,LDB).

O alcance desse perfil dá-se pela ênfase nas competências e habilidades em todas as áreas do conhecimento da educação Básica, e são esses requisitos que dão base à elaboração das questões relativas aos exames nacionais. $\mathrm{O}$ ENEM possui objetivos específicos, como :

- oferecer um subsídio para cada cidadão realizar sua auto-avaliação, com vistas às futuras escolhas, tanto em relação ao mercado de trabalho quanto à continuidade de estudos;

- servir como modalidade alternativa ou complementar aos processos de seleção nos diferentes setores do mundo do trabalho;

- servir como modalidade alternativa ou complementar aos exames de acesso aos cursos profissionalizantes pós-médios e ao ensino superior.

O exame do ENEM é realizado anualmente e destina-se a todos os concluintes e os egressos do ensino médio, independentemente de quando o tenham concluído, podendo o candidato partici- par de tantas provas quantas vezes achar necessário.

De outra parte, temos o PROVÃO ou o Exame Nacional de Cursos, que é uma prática avaliativa, cujo objetivo é alimentar os processos de decisão e de formulação de ações voltadas para a melhoria dos Cursos de Graduação. Os conteúdos da prova são definidos por uma comissão específica para cada curso, considerando a diversidade dos elementos compartilhados pelos projetos pedagógicos das Instituições. Todos os alunos que concluírem o curso deverão prestar o Exame, que é condição obrigatória para a obtenção do registro do diploma. As inscrições são de responsabilidade exclusiva da Instituição.

Diante dos esclarecimentos das diversas formas de avaliação, afirmamos que é um tema bastante controvertido por polarizar as adesões a favor ou contra o Sistema de Avaliação da Educação Básica implantado pelo Ministério da Educação e Cultura (MEC) e, no Estado de São Paulo, com o nome de SARESP (Sistema de Avaliação de Rendimento Escolar), coordenado pela Secretaria da Educação do Estado. Os que são favoráveis advogam a importância do sistema central controlar a qualidade do ensino da rede nacional, assim como o fazem os países mais avançados. $E$ aqueles que são contra o negam, em defesa de uma democratização das escolas, posicionando-se totalmente contrários à centralização de ações controladoras.

À vista de tantas contradições, propusemos realizar um levantamento de legislações pertinentes a essa polêmica, com o intuito de refletirmos sobre a concepção da avaliação,isto é, o quê, como, para quê avaliar e a quem beneficia.

Procuramos realizar a pesquisa, mantendo a neutralidade, na medida do possível, quanto às questões ideológicas; entretanto, algumas considerações de caráter subjetivo podem dar a entender que a autora assume uma posição objetiva no trato do assunto - relação subjetividade e objetividade do pensamento com a formação - e, portanto, esclarecemos aos leitores a possibili- 
dade de dupla interpretação: a de quem escreve e a de quem lê, respeitada a individualidade de cada pessoa.

O levantamento bibliográfico teve o intuito de apresentar também à comunidade acadêmica as mudanças positivas e negativas provocadas pela avaliação, tanto em nível de Instituição quanto em nível de valores e atitudes dos alunos e também da própria sociedade.

A Avaliação Institucional foi criada pelo MEC com o objetivo de estimular a adoção de processos de excelência ${ }^{1}$ no ensino em todas as Instituições de Ensino Superior Brasileiro. Visa, ainda, criar e consolidar uma cultura de avaliação em toda rede nacional; acompanhar o desenvolvimento de cada curso; desenvolver uma mentalidade participativa e crítica entre os acadêmicos; atualizar, continuamente, os projetos pedagógicos de graduação e envolver a comunidade externa nos assuntos institucionais.

Ao ser instituído, procurou-se preservar a identidade institucional com o estabelecimento do perfil, missão, condições, necessidades e aspirações da instituição, mediante um processo de adesão com a participação de toda a comunidade acadêmica.

Para melhor entendermos o estatuto legal, selecionamos e transcrevemos alguns dispositivos que merecem um estudo:

\section{Lei de Diretrizes e Bases da Educação} Nacional de 1996

Artigo 9ํo -inciso VI - “à União caberá assegurar processo nacional de avaliação do rendimento escolar no ensino fundamental, médio e superior , em colaboração com os sistemas de ensino, objetivando a definição de prioridades e a melhoria da qualidade do ensino".

Decreto n. 2026 de 10/10/1996 estabelece procedimentos para o processo de avaliação dos cursos e instituições de ensino superior:
Artigo $1^{\circ}$ - O processo de avaliação dos cursos $e$ instituições de ensino superior compreenderá os seguintes procedimentos:

I- análise dos principais indicadores de desempenho global do sistema nacional de ensino superior...

II- avaliação do desempenho individual das instituições de ensino superior, compreendendo todas as modalidades de ensino, pesquisa $e$ extensão,

III- avaliação do ensino, de graduação, por curso, por meio da análise das condições de oferta pelas diferentes instituições de ensino e pela análise dos resultados do Exame Nacional de Cursos,

IV- Avaliação dos programas de mestrado e doutorado por área do conhecimento

Art. 4ำ- A avaliação individual das instituições de ensino superior....considerará os seguintes aspectos :

I- administração geral;

II- administração acadêmica (currículo, habilidades, regimento e avaliação;

III- integração social : instituição $X$ comunidade;

IV- produção científica, cultural e tecnológica.

Decreto 2306 de 19 de agosto de 1997

Artigo 14 - A autorização e o reconhecimento de cursos e respectivas habilitações e o credenciamento das instituições de ensino superior do sistema Federal de Ensino, organizadas sob quaisquer das formas previstas neste Decreto, serão concedidos por tempo limitado, e renovados periodicamente após processo regular de avaliação.

Parág. $2^{\circ}$ - Os procedimentos e as condições para a avaliação e reavaliação, para o credenciamento, descredenciamento e recredenciamento das instituições de ensino superior do sistema Federal de Ensino, serão estabelecidos em ato do Ministro de Estado da Educação e do Desporto, atendidas as disposições do Decreto n. 2026 de 10 de outubro de 1996.

'Excelência - termo utilizado para designar a qualidade de ensino e esta sugere uma "aprendizagem estratégica" (quem aprende, o que se aprende, como se aprende, e por quê se aprende). 
Portaria n. $\stackrel{0}{302}$ de 07 de abril de 1998 - regulamenta o processo de avaliação nas instituições de Ensino Superior.

Art. 1ํ. A avaliação do desempenho individual das instituições de ensino superior, compreendendo todas as modalidades de ensino, pesquisa e extensão, conforme disposto no art. ${ }^{\circ}{ }^{\circ}$, inciso II do Decreto 2.026 de 1996, , será realizada pela Secretaria de Educação Superior - SESU - no âmbito do Programa de Avaliação Institucional das Universidades Brasileiras - PAIUB.

\section{Art. 2․ - O processo de avaliação de que trata} o artigo anterior constitui uma atividade permanente e compreende:

I- processo de auto-avaliação, conduzido pela própria instituição, observadas as orientações e parâmetros estabelecidos pela SESU, ouvido o Comitê Assessor;

II- avaliação externa, a qual incluirá visita in loco, observadas as orientações e parâmetros estabelecidos pela SESU, ouvido o Comitê Assessor;

III- apreciação dos relatórios da avaliação interna e da avaliação externa pelo Comitê Assessor do PAIUB, bem como de quaisquer outros procedimentos avaliativos ocorridos na instituição.

Art. 6ํ. Os resultados da avaliação do desempenho individual das instituições de ensino superior serão incorporados aos relatórios da SESU para fins de autorização e reconhecimento de cursos, credenciamento e recredenciamento de Instituições e utilizados na orientação de outras políticas do Ministério da Educação e do Desporto de qualificação do ensino superior.

As legislações acima selecionadas e por nós sublinhadas permitem-nos analisar e afirmar o seguinte:

- à União compete a avaliação nacional das universidades;

- o credenciamento e o recredenciamento dos cursos dependem dos resultados da avaliação das faculdades;
- a avaliação de desempenho individual é de responsabilidade de cada instituição;

- a avaliação institucional deve ser uma atividade constante e permanente;

- a avaliação de desempenho individual compreende apreciação da gestão universitária administrativa , acadêmica, de pós-graduação, pesquisa e extensão.

Diante dessa análise, concluímos que a concepção de avaliação educacional a que o legislador está se referindo é a avaliação democrática em que há envolvimento de todos com vistas ao bom desenvolvimento e funcionamento qualitativo da Instituição. O aluno é a razão de ser da escola e, por isso, a avaliação centra-se no processo de ensino, cuja satisfação e interesse dos alunos devem ser o foco de atenção dos educadores. Tornar o aluno ativo, respeitando suas potencialidades, é a meta principal nesse processo.

Os pressupostos básicos da democracia estão presentes, na medida em que se esperaa participação de toda a comunidade acadêmica, nas diferentes instâncias da avaliação, de uma forma dialogal, horizontal entre os iguais, e de forma transparente nas ações e nos resultados da avaliação.

Com a instituição legal da avaliação e sua implementação gradual pelas faculdades, esperase formar cidadãos aptos a entenderem e participarem do processo de desenvolvimento da sociedade, por isso a avaliação funcionará como instrumento de melhoria da qualidade de ensino, identificando problemas para corrigir os erros e introduzir mudanças.

A melhoria da qualidade de ensino visada pela avaliação traduz-se na melhoria das relações sociais na sala de aula, no espaço acadêmico, entre todos os envolvidos na tarefa institucional que é a de ensinar e aprender, ou seja, sob o lema do "aprender a aprender", que significa uma aprendizagem expressiva com formatos diferentes, numa relação interativa entre alunos e professores. Então, vimos que a concepção de avaliação, discutida até aqui, é a democrática, 
voltada para a qualidade de ensino, para fazer frente às exigências do mercado global.

A avaliação proposta pelo MEC se realiza em etapas . A primeira é denominada de avaliação interna, em que a Instituição realiza a autoavaliação com foco em programas, metodologias de ensino, bibliografias atualizadas, capacitação de docentes e programas de avaliação. A segunda é denominada avaliação externa, quando uma comissão de especialistas irá verificar a auto avaliação da Instituição, a avaliação de cursos, o resultado do provão, a avaliação da CAPES e análise dos indicadores de desempenho global. Em síntese, a comissão de especialistas estará focando a administração geral, a administração acadêmica, a integração social -instituição e meio social via extensão - e a produção científica, cultural e tecnológica .

A segunda etapa a considerar agora é para quê avaliar? Justificam-se as avaliações em nome da excelência no ensino que se verifica através da avaliação do professor, do aluno e do administrador. Mas a excelência do produto, ou seja, do aluno, só se dá mediante a reformulação da Instituição no seu todo, desde a mudança estrutural que dê condições de trabalho ao professor até a introdução de uma cultura de avaliação participativa e sempre com vistas a melhoria do ensino e, portanto, a melhoria da qualidade de ensino do professor. Por isso, o princípio de ajuda está presente em toda avaliação, desde a fase da sondagem, do diagnóstico da situação ,à fase da execução ou da auto- avaliação até à fase da avaliação externa. Ajudar o professor a melhorar em seu trabalho específico, oferecendo subsídios para elaborar um plano de ensino, reformular o conteúdo, utilizar-se de metodologias diversificadas e avaliar os alunos no sentido formativo. Ajudar o administrador a tomar decisões quanto ao pessoal, recursos materiais e físicos. Ajudar o aluno a tomar decisões em situações-problema, com senso crítico transformador e com responsabilidade profissional e social.

A viabilização dessa ajuda se dá, quando a Instituição oferece condições iniciais de trabalho, que podem ser verificadas por meio da avaliação do nível de motivação dos alunos, pela caracterização do perfil sócio-econômico e cultural deles, pela verificação do domínio de conteúdo e das metodologias(técnicas) empregadas pelo professor, e pelas condições institucionais de trabalho oferecidas ao professor como o tamanho das turmas, o acervo da biblioteca, o laboratório, o auditório e outros.

Um outro instrumento de acompanhamento e de ajuda ao professor diz respeito ao seu trabalho específico na sala de aula, enquanto condições de processo, verificando, por meio de questionários ou portfólios ${ }^{2}$ a organização do trabalho pedagógico do professor, a utilização diversificada de métodos e técnicas de ensino, a concepção e forma de avaliação dos alunos, analisando a relação professor-aluno e as formas de "feedback" empregadas.

E, como condição de produto do trabalho de uma Instituição, teríamos alunos satisfeitos, com bom rendimento escolar e desempenho acadêmico e profissional, o que nos garantiria ter havido mudança de atitudes e valores.

Colocadas essas três condições como parâmetro de excelência, passamos a considerar a terceira etapa da análise que é: o quê avaliar?

- Avalia-se o aluno em seu crescimento na vida acadêmica. É' necessário verificar a apreensão de conteúdos das disciplinas, e a aplicação dos conhecimentos e princípios adquiridos na disciplina em situações reais da vida cotidiana e da vida profissional;

-Avalia-se o professor em seu desempenho na sala de aula. É' necessário o aprimoramento da qualidade das aulas com programa atualiza-

${ }^{2}$ Portfólio - compilação de trabalhos dos alunos, tais como resumos, cartazes, apontamentos, diários em pastas, fichas, CDROM etc. 
do, bom desempenho metodológico e de avaliação dos alunos;

- Avalia-se o curso verificando a adequação, a coesão e a consistência das disciplinas dentro do currículo. Analisa-se também a importância de cada disciplina, a relação interdisciplinar que ela estabelece e a relação dialética com o contexto social;

-Avalia-se a Instituição no seu todo, envolvendo todos os setores que dão suporte ao ensino .

Como quarta etapa, temos a questão como avaliar?

Há várias formas de se avaliar, mas a mais freqüente é o questionário.

As questões que mais correspondem ao propósito da avaliação são categorizadas em:

- percepção dos alunos;

- expectativas dos alunos;

- dinâmica da sala de aula (motivação e interação);

. conteúdo;

. metodologias;

. avaliação.

Com o intuito de colaboração, podemos citar alguns exemplos para :

- avaliar o aluno

- atividade de conselho de classe;

. formação de portfólio de avaliação;

. instrumentos de avaliação de cada disciplina.

- avaliar o professor

- avaliação inicial do programa e planejamento das aulas;

- acompanhamento do programa e do desempenho do professor , através de avaliação por questionário junto aos alunos e encontro com grupos de alunos;

- comparação com os resultados do instrumento de avaliação da Instituição;

por professor.

- formação de um portfólio de avaliação

- avaliar o curso
. avalia-se através de grupos de trabalho entre os professores;

- comparação da evolução das turmas;

- comparação dos resultados das avaliações de professores e alunos;

- provas de verificação.

Como quinta etapa de consideração, temos a pergunta: quem se beneficia com essa avaliação? $\mathrm{O}$ aluno foi o ponto de partida de toda essa análise de avaliação e nele se volta , desta vez mudado, assim o esperamos, com valores condizentes a um profissional comprometido, crítico e transformador . Por isso, a avaliação visa a um ensino estratégico voltado para um resultado positivo.

Entretanto, o alcance dessa meta implica em esforço da grande maioria da Instituição associada à vontade política para o envolvimento consciente de todos . Para tal, é necessário um período de sensibilização, por meio de vários contatos e comunicações às pessoas envolvidas na Instituição, para garantirmos a efetivação da política educacional de avaliação nacional das instituições.

Posicionando-nos a favor dessa avaliação, surgem outras indagações:

. existe um parâmetro de indicador de qualidade?

- qual é o indicador que define o bom desempenho?

. qual é o fundamento científico desses indicadores?

Existem alguns indicadores de avaliação que o MEC estabeleceu, tendo como parâmetro o definido pelo PAIUB, os quais procuramos sintetizar aqui:

I- No plano Institucional - a coerência entre a missão, regimento e gestão acadêmica.

II- No plano da Gestão Universitária -a articulação e o funcionamento orgânico da administração, das formas de decisão, dos suportes administrativos ( sistema de comunicação, os colegiados ). 
III- No plano Acadêmico - a clareza dos objetivos e metas, um perfil profissional definido com a formação condizente; um currículo atualizado, articulado com a teoria e a prática; uma prática docente com a gestão acadêmica atrelada a um planejamento, conteúdo e metodologia; um recurso humano capaz de avaliar-se, de avaliar e ser avaliado pelos alunos; uma infra-estrutura adequada para o bom funcionamento e alcance dos objetivos; um enfoque curricular voltado às necessidades sociais e éticas profissionais. Ainda no plano acadêmico, a eficiência e eficácia do curso, verificáveis pelo número de evasão, repetência, promoção e pelo nível de motivação e satisfação dos alunos, além de atender às demandas da sociedade e dos estudantes para o seu desempenho profissional.

IV- No plano da pós-graduação - alguns indicadores de qualidade são apontados como a relação pesquisa, ensino e extensão; as bolsas de estudo; sistema de incentivo aos doutores; carga horária docente dedicada à pesquisa; a participação em eventos científicos; envolvimento em programas e projetos de pesquisa. Em relação à pesquisa- a relevância da área do conhecimento; os relatórios de pesquisa; as publicações e apresentações em eventos científicos. E, em relação à extensão, a interface com o ensino de graduação; a procura da sociedade pelos serviços; o nível dos cursos ofertados e a relevância social dos cursos oferecidos.

Segundo as conclusões tiradas no Fórum Reflexivo da UDESC (Universidade do Estado de Santa Catarina) em 1995, os indicadores para avaliação de disciplinas e Desempenho Docente são definidos em:

\section{Na disciplina:}

- plano de ensino;

- fontes de consulta;

- procedimentos didáticos;

- instrumentos de avaliação;

- conteúdo de avaliação;
- atividades práticas;

- carga horária;

- seqüência de conteúdo;

- conhecimento anterior;

- tempo dedicado às atividades extra classe relacionadas com a disciplina;

- freqüência;

- infra-estrutura;

- adequação do conteúdo ao nível de exigência;

- interdisciplinaridade;

- número de alunos;

- situação do acadêmico em relação à disciplina.

\section{No desempenho docente:}

- domínio do conteúdo;

- modo de apresentação e didática;

- pontualidade;

- atendimento extraclasse;

- assiduidade;

- incentivo à participação;

- relacionamento com os alunos;

- didática;

- motivação tipos de avaliação;

- incentivo e participação;

- atualização;

- articulação teórica e prática;

- imparcialidade.

Esses indicadores, discutidos e definidos no Fórum, permitem à comissão de professores da avaliação institucional elaborar a avaliação em cada unidade.

Para cada grupo avaliado, verificam - se os desempenhos abaixo categorizados:

\section{- Como recurso interno:}

- perfil sociocultural do aluno ingressante; . bagagem dos conhecimentos específicos, habilidades;

- comportamentos e atitudes em relação ao curso e à profissão;

- expectativas em relação à vida universitária;

. expectativas em relação à vida profissional futura. 


\section{- Perfil do aluno matriculado:}

. satisfação/insatisfação face às expectativas iniciais;

. mudança de curso/ trancamento/ transferência;

. desempenho do aluno visto pelo aluno;

. desempenho do aluno visto pelo professor;

- desempenho do aluno visto pelo colegiado do curso.

\section{- Perfil do professor:}

- perfil sócio intelectual;

. experiência docente;

. titulação formal;

- desempenho acadêmico visto pelo aluno;

desempenho acadêmico visto pelo professor;

- desempenho acadêmico visto pelos pares;

- envolvimento em atividades acadêmicas e administrativas;

- produção científica e intelectual.

\section{- Perfil do corpo docente:}

- titulação formal;

. dedicação ao trabalho acadêmico;

- trabalho/produtividade (ensino, pesquisa, extensão).

\section{- Perfil dos recursos humanos:}

- espaços físicos e edificações;

. equipamentos e instalações;

- laboratórios e outras instalações de ensino, pesquisa e assistência à comunidade;

. acervos bibliográficos;

- acervos culturais;

.serviços (transportes, alimentação, comércio, correios, telefones, bancos de dados etc.).

\section{- Processos:}

. administração geral : - planejamento e acompanhamento;

. administração setorial:
. de pessoal;

. de material;

. do patrimônio;

. de serviços gerais;

. de serviços complementares;

- financeira e contábil.

- administração acadêmica:

- plano de trabalho docente;

- programação da disciplina;

. avaliação da aprendizagem;

. controle acadêmico;

- administração de pesquisa;

. administração de cultura e extensão.

\section{- Em relação ao produto/resultado -}

- perfil sócio econômico do profissional egresso:

. empregabilidade do curso;

- progressividade profissional;

. desvio funcional/ profissional.

\section{- Perfil da produção científica e intelectual:}

. indicadores de produtividade e representatividade;

. indicadores de relevância da produção científica;

. utilidade do trabalho científico;

- relevância na prestação de serviços, técnicocientíficos, culturais e assistenciais.

Os dispositivos e as orientações traçadas pelo poder público central e postas como política educacional brasileira retratam o momento de mudanças rápidas pelas quais o sistema está passando, quer pelos efeitos da globalização, quer pela necessidade urgente de ajustes à nova realidade social através da educação. A política educacional, concretizada na LDB n. 9 9394/96, é o resultado de acordos entre os países da América e da Europa. A nova ordem econômica é a simultaneidade de produção, de mercado, de organização e de trabalho, tudo, em tempo real, por todo o planeta. A informática e o seu simples "clicar" no mouse facilita essa globalidade. Até 
mesmo o mercado financeiro está informatizado! Está desaparecendo a relação capital e trabalho do período econômico industrial. É preciso um profissional que dê conta dessa mudança e se engaje conscientemente nesse mundo para transformá-lo num mundo mais humano e justo.

A inclusão da avaliação institucional nos textos da LDB/96, deixada sob a responsabilidade de órgão central de administração, revelanos a preocupação do sistema em emparelhar-se nos movimentos da globalização e adequar-se num sistema moderno, inserindo-o numa sociedade pós-moderna. Assim, vimos as grandes reformas estruturais administrativas e didáticas da educação nacional expressas em artigos de lei e operacionalizadas em cada sistema, dando autonomia para a organização da Educação Básica e Superior.

Vimos a concretização da avaliação externa, com a instituição, em 1996, do SARESP (avaliação do ensino fundamental -especificamente em Português e Matemática ); em 1998, a instituição do ENEM (avaliação do ensino médio) e, em 1996, o PROVÃO NACIONAL(avaliação dos cursos de graduação). A efetivação também da avaliação interna das instituições, sob a responsabilidade de uma comissão de professores, que, em trabalho de assessoria junto à direção e à coordenação, executam as avaliações acadêmicas, elaborando questionários aos alunos, aos professores e verificando a compatibilidade do currículo e a gestão desse currículo, tendo como norte a melhoria do ensino em consonância com o projeto pedagógico(missão) da universidade .

Se nos EUA, Inglaterra, França e Espanha, a avaliação institucional faz parte da rotina da administração, e envolve toda a comunidade acadêmica, para nós, a avaliação institucional é algo inovador e até mesmo motivo de resistência dos acadêmicos, dada a nossa cultura conservadora . Muitos - professores e administradores entendem-na instrumento de punição, de coação e repressão e oferecem resistência à mudança. É nesse sentido que se faz urgente um trabalho de esclarecimento e de conscientização da importância da avaliação.

A realidade atual, nas Instituições, ainda está em fase embrionária; há um confronto de muitas opiniões contraditórias, entre elas, o entendimento de que a avaliação é um instrumento que mede o nível cognitivo do aluno, e outra, de que a avaliação tem caráter formativo, por fazer os alunos participarem do seu próprio desempenho escolar.

Enquanto comissão de professores de avaliação do Centro Universitário Sant'Anna, cumpre-nos esclarecer que avaliar é um processo complexo, que envolve, ao mesmo tempo, a avaliação tradicional, avaliação formativa e certificadora. Todo processo de ensino é mediado pela avaliação formativa, porque orienta o ensino, através de vários recursos didáticos e relações negociadoras entre os alunos e professores. Avalia-se para diagnosticar e perceber a inadequação ou não das estratégias de aprendizagem. Ao mesmo tempo, avalia-se para controlar uma ordem disciplinar, pedagógica, educacional e também para certificar a formação. A entrega do diploma é precedida de avaliação. $\mathrm{O}$ meio externo também requer avaliação para o seu controle de preferência. Em situações de sala de aula, a avaliação adquire vários formatos, desde aquela que regula a vontade dos alunos, de "preparar para a prova", até a avaliação contratual entre professor e alunos no processo didático de ensino.

Isto posto, a avaliação possui, nos termos de Perrenoud (1999), duas lógicas: a de certificação, por onde se faz necessário avaliar o estudante em seu rendimento escolar, e a de formação, quando ajuda o aluno a aprender e a se desenvolver, com todas as mediações das intervenções reguladoras do professor, da comunicação interativa e da didática como meios de controle da situação de aprendizagem.

Podemos, por isso, afirmar que avaliar é conviver com as situações contraditórias de educar. Nós formamos através da orientação e controle, ao mesmo tempo em que estamos selecionando 
e comparando o educando. Quanto mais se intenciona instruir, mais tendemos a selecionar. O que fazer? É procurar atenuar a lógica seletiva da avaliação, buscando meios alternativos de ação e, no caso, a pedagogia alternativa de estratégias. Essa pedagogia pode dar conta de trabalhos diversificados, construtivistas e cooperativos.

Face ao exposto, cabe àqueles que cuidam da avaliação, na qual me incluo, engajarem-se nesse processo de esclarecimento aos colegas e tomarem uma posição de ajudar a construir uma avaliação que ensine os professores a enxergarem as dificuldades de seus alunos, passando a ensinar de maneira diferente. Aprender a avaliar as competências através das observações qualitativas dos fatos e gestos, palavras, raciocínios, hesitações, decisões, caminhos do sujeito frente a um problema.

Saber que avaliar é observar, dialogar e proporcionar a auto-avaliação. E, mais ainda, avaliar competências implica na utilização de um conjunto de atividades educativas a começar pelo contexto, domínio de conteúdo e suas possibilidades, domínio de várias estratégias de ensino para incentivar a colaboração entre os pares, o estímulo à cognição e à metacognição dos alunos, à utilização de vários critérios de correção; avaliar as aptidões dos alunos, seus conhecimentos anteriores e o grau de domínio das competências.

Como último comentário, é bom lembrar que, junto da comissão de professores responsáveis pela auto-avaliação da Instituição deveria trabalhar um outro grupo, denominado de apoio pedagógico, que seria responsável pela orientação técnica aos professores, oferecendo cursos, informações sobre a organização de aula, as habilidades de inovação, a gestão do tempo de aula, a utilização de critérios de avaliação, as competências em métodos de ensino e o "feedback" aos alunos.

\section{REFERÊNCIAS BIBLIOGRAFICAS}

SOUZA, Eda C.B. Machado - Avaliação de Disciplina - Curso de Especialização em avaliação à distância - V. 2 -Brasília,1997.

-Brasília, 1998. Avaliação em Instituição Superior - Curso de Especialização em Avaliação a Distância - V. 6

-Brasília,1997. Técnicas e Instrumentos de Avaliação - Curso de Especialização em Avaliação à distância - V. 1

PERRENOUD, Philippe - Avaliação - Porto Alegre: Artmed, 1999.

BICUDO, Maria Aparecida V. - Formação do Educador e Avaliação Educacional - UNESP, 1999.V.1 e 2

Avaliação Institucional -Proposta de Avaliação Institucional e Fórum Reflexivo do Projeto Pedagógico . UDESC, 1995 e 1996.(mimeog)

Avaliação Institucional - PAIUB, 1998 (mimeog.)

Revista da FDE - Sistemas de Avaliação Educacional - Idéias no 30, 1998. 